Mendoza Mejía, J. A., Therán Barajas, C. E., y Vásquez Vargas, L. C. (2013). Juventud en el municipio de Barrancabermeja: problemáticas socioeconómicas y participación. Revista Lebret (5). Bucaramanga, Colombia: Universidad Santo Tomás, pp.163-183

\title{
Juventud en el municipio de Barrancabermeja: problemáticas socioeconómicas y participación*
}

\section{Youth in the municipality of Barrancabermeja: socioeconomic issues and participation}

José Alejandro Mendoza Mejía Carmen Elisa Therán Barajas ${ }^{2}$ Lizeth Caterine Vásquez Vargas

\begin{abstract}
Resumen
En este documento se caracteriza la situación actual de la población joven del municipio de Barrancabermeja y los procesos de articulación de las organizaciones juveniles en el periodo 2004 - 2010. Así, en la medida que los jóvenes narran la forma en que sus organizaciones se consolidaron y adaptaron a los cambios sociales, fueron identificadas problemáticas socioeconómicas asociadas a la pobreza y la falta de oportunidades y problemáticas de capacidad de gestión que inciden en la participación juvenil.
\end{abstract}

Palabras clave

Juventud, Participación Juvenil, Organizaciones Juveniles

Códigos de Clasificación JEL: I38, J13, Z13

\begin{abstract}
This paper characterizes the present situation of the youth population of the town of Barrancabermeja and the joint processes of youth organizations during the period 2004-2010. Thus, as young people talk about how their organizations were consolidated and adapted to social changes, it was possible to identify socioeconomic issues associated with poverty and lack of opportunities, and problems related to management capacity affecting youth participation.
\end{abstract}

Keywords

Youth, Youth participation, Youth organizations

* El articulo presenta algunos resultados de la investigación "Política pública y capital social juvenil en el municipio de Barrancabermeja 2004- 2010" financiada por el Programa de Jóvenes Investigadores de Colciencias. Grupo de Investigación Economía Social y Desarrollo Empresarial, Facultad de Economía, Universidad Santo TomásBucaramanga Colombia

1 Economista. Joven Investigador de Colciencias 2011- 2012. Facultad de Economía, Universidad Santo TomásBucaramanga. Colombia. Correo electrónico: jose14_280@hotmail.com

2 Magister en Ciencias Económicas y Magister en Administración de Empresas. Líder Grupo Economía Socia y Desarrollo Empresarial, Facultad de Economía, Universidad Santo Tomás- Bucaramanga. Colombia. Correo electrónico: ctheran59@gmail.com

3 Economista. Estudiante de Maestría en Desarrollo Rural, Universidad Nacional de Costa Rica. Profesora Universidad Santo Tomás- Bucaramanga Colombia. Correo electrónico: caterinvv@gmail.com 


\section{Introducción}

Durante la segunda mitad del siglo XX la "juventud" emerge con ímpetu en todo el mundo, no sólo como fuerza social que lidera movimientos de cambio, sino como centro de un debate académico que intenta caracterizarla desde diferentes perspectivas, o como objeto de la política pública que reconoce su problemática y se esfuerza por delimitar propuestas para su solución. Muñoz (2003) afirma que "cuando se analiza con paciencia la literatura sobre el tema, anterior a los años sesenta, es fácil hacer un balance de estereotipos que se mueven en el espectro de la "rebeldía" y la "esperanza", ambos de corte romántico" (p.3) y en un artículo reciente al referirse a este proceso en Europa, René Bendit (2004) plantea que el imaginario social se mueve permanentemente entre la imagen de la "juventud como recurso" y la "juventud como problema". De acuerdo con la primera, dice el autor mencionado (2004):

La juventud representa el futuro idealizado; los jóvenes son el receptáculo de los valores que cada generación transmite a la siguiente y, por consiguiente, son un recurso al cual se le deben otorgar las mejores oportunidades posibles de desarrollo. Sin embargo, al mismo tiempo, la juventud también es percibida como un problema, como una fuente de peligro o como un período vulnerable en respuesta al cual se deben idear medidas protectoras. Las dos imágenes no son contradictorias, sino que más bien se complementan y se acentúan mutuamente (p.52).

Esa visión bipolar ha marcado también el debate reciente en América Latina y es referente obligado para hablar de la situación de la política pública en nuestro país, en la medida que ésta responde a un esfuerzo fragmentado entre el deseo de aprovechar el enorme potencial de las energías generacionales en formación y la necesidad de "domesticarlas" con el fin de evitar su desbordamiento.

La investigación es explicativa- descriptiva con un enfoque cualitativo. A partir del análisis de la documentación disponible y de información primaria obtenida en grupos focales y entrevistas estructuradas se intenta caracterizar la problemática de este grupo poblacional en el municipio de Barrancabermeja - centro del Magdalena Medio Santandereano y, por tanto, espacio de conflicto y confrontación durante mucho tiempo - atendiendo de manera especial la percepción de los propios protagonistas sobre su realidad. En el curso del estudio, se identifican las limitantes institucionales en el momento de la formulación de programas y proyectos para, finalmente, realizar un recorrido por los procesos de articulación de las organizaciones juveniles que han surgido en el escenario regional para convertirse, de algún modo, en actores importantes del entramado social. 


\section{Problemática juvenil en el municipio de Barrancabermeja}

El municipio de Barrancabermeja, principal puerto sobre el río Magdalena y mayor centro poblado de la región del Magdalena Medio Colombiano, localizado en la provincia de Mares al occidente del Departamento de Santander, tiene una extensión de $1.154 \mathrm{Km}^{2}$ y está conformado por siete comunas y seis corregimientos (La fortuna, El Llanito, El centro, Ciénaga del Opón, San Rafael de Chucurí y Meseta San Rafael). De acuerdo con proyecciones del Departamento Administrativo Nacional de Estadística- DANE, la población del municipio para el año 2012 es de 191.718 habitantes, siendo 45.672 jóvenes que representan un 23,82 \% de la población total.

Barrancabermeja es un importante centro de producción ganadera, aurífera, carbonífera y petrolera. Allí se localiza la mayor refinería del país, recibiendo la denominación de "capital petrolera de Colombia". Igualmente es un puerto fluvial estratégico y paso obligado de la Ruta del Sol que comunica el centro y norte del país. Sumado a esto, el ámbito sociopolítico evidentemente no se ha inmovilizado ante estas singularidades productivas y económicas, por el contrario, en la región se han desarrollado procesos inquietantes que demuestran las dinámicas permanentes de la zona: el municipio ha sido desde los años 40 del siglo pasado receptor de un gran número de familias desplazadas por la violencia; por otro lado, los movimientos sindicales cuentan con una la innegable importancia social e histórica de los movimientos sindicales, y un complejo contexto social por la participación de los grupos al margen de la ley (guerrillas y paramilitares) quienes interesados en las evidentes riquezas y potencialidades del municipio lo convirtieron en un fortín en disputa.

\section{Juventud, ilegalidad y conflicto armado}

Según Quijano y Díaz (2004) desde los años ochenta del siglo pasado, grupos armados ilegales de izquierda, principalmente el Ejército de Liberación NacionalELN sentaron sus bases de apoyo en el municipio de Barrancabermeja construyendo nexos con sus pobladores a través de una relación de utilidad económica con las bandas dedicadas al hurto de gasolina y un discurso político reivindicativo que respondía a las necesidades y carencias de un amplio sector social, especialmente los barrios de los sectores sur y nororientales. En este contexto, tal como señala Molina (2008) en el imaginario local de Barrancabermeja se territorializó el conflicto y la pobreza en las comunas de la zona oriental, situación que trajo consigo una segregación de la sociedad y mayores dificultades de acceso a oportunidades para los jóvenes más vulnerables del municipio, quienes eran indiscriminadamente señalados de pertenecer a grupos al margen de la ley.

[...] en ese momento había una problemática muy grave que era que los chicos se iban a los grupos armados y entraban a hacer parte de la guerra. Esta es 
la comuna siete, es un punto álgido, todo el suroriente de Barrancabermeja estaba específicamente señalado por eso y se hablaba del puente para arriba y del puente para abajo, entonces pareciera ser que los jóvenes del puente abajo eran mejores y eran personas, mientras que los jóvenes del puente para arriba solamente eran delincuentes, entonces eso hacía que los muchachos carecieran de todo tipo de oportunidades (entrevista 11, Octubre 2012).

Para finales de los años noventa, el paramilitarismo toma el control de los sectores populares del municipio y establece "complejos sistemas de vigilancia reticular" (Caraballo, 2010, p.71) que les permitió ejercer control sobre los pobladores y definir normas de convivencia en su territorio de influencia. Un antiguo líder juvenil de la Comuna Siete en alusión a las problemáticas juveniles bajo el contexto del conflicto armado, afirma que:

Han variado algunas, pues cada época tiene sus propios problemas. En su momento el tema en Barrancabermeja, era que los jóvenes [...] el miedo a la estigmatización, entonces los jóvenes de los barrios surorientales eran estigmatizados por ser guerrilleros, subversivos. Hasta el final de los 90. Luego al principio del 2000, ya era el tema de la moda, entonces ya no podían andar con aretes, con un peinado distinto que fuera extraño, la ropa. Entonces ya había mucho riesgo. Salir tarde en la noche, era un riesgo para los jóvenes (entrevista 5, septiembre 2012).

Además, ligada a las condiciones de vulnerabilidad presente en ciertos sectores populares de la ciudad y el recrudecimiento de las acciones de grupos al margen de la ley, se dio un florecimiento de actividades ilegales en Barrancabermeja a manos del paramilitarismo que "utilizó la violencia para hacerse al control de las actividades económicas legales e ilegales en la región” (Vargas, 2009, p.457). Un claro ejemplo fue el contrabando de gasolina.

Esta actividad económica ilegal, como lo refiere Moreno (2006), fue aplicada para profundizar una relación de dependencia con la población, generando simultáneamente procesos desestructuradores de las relaciones sociales. Ariza y Cardona (2005) al abordar la situación de los jóvenes de la Comuna 7 de Barrancabermeja en el contexto del conflicto urbano encuentran que los jóvenes jugaron un papel de importancia en los modos de producción ilegal en la medida que desarrollaban "la mayor parte de las dinámicas necesarias para el adecuado funcionamiento de las cadenas de tráfico de gasolina en la zona" (p.89). Los autores identifican como consecuencias de la práctica de esta actividad ilegal para los jóvenes de la comuna siete:

La estigmatización de jóvenes de otras comunas, adultos e instituciones donde en muchos casos ser joven de la comuna es sinónimo de ser "cartelero", pero también una lógica de ingreso donde la relación adquisición de dinerocapacidad de gasto - capacidad de dinero, resultado siendo bastante rentable en relación con el tiempo y el esfuerzo dedicado a dicha labor, aspecto que entre en competencia, sin igualdad alguna de condiciones con los proyectos productivos enmarcados en la legalidad (Ariza y Cardona, 2005, p.88). 
Un líder juvenil de la Fundación Nuevo Amanecer comenta que esta actividad ilegal también involucraba a jóvenes de la comuna 3, quienes carecían de oportunidades laborales e identificaban en el contrabando de gasolina una fuente de ingresos a pesar del riesgo latente que corrían sus vidas en los constantes enfrentamientos con la fuerza pública.

Hacia el año 2006 en Barrancabermeja existía algo que era el contrabando de gasolina, por lo tanto [sic] en la comuna tres, exactamente entre los barrios Belén, Colinas y San Silvestre, pasaba un tubo de oleoducto de gasolina el cual había sido ya de conocimiento para los grupos armados, [...] la gasolina se había convertido en contrabando, el cual afectaba a los jóvenes, porque la mayorías de las personas que trabajan en el contrabando de la gasolina eran jóvenes. Entonces, cuando surgía un enfrentamiento entre la policía y los grupos armados, digamos que los afectados eran los jóvenes, [...] entonces veíamos a diario como los jóvenes de nuestro alrededor, pues morían en esos enfrentamientos. Simplemente porque no había oportunidad de trabajo para los jóvenes (entrevista 8, Septiembre 2012).

\section{Microtráfico y drogadicción}

La dinámica del conflicto ha cambiado y se ha conjugado con otras variables que complejizan la situación de la Juventud. Según Camargo (2011), la creciente situación de inseguridad en las ciudades colombianas es consecuencia de una disputa por el control de las actividades delincuenciales y el microtráfico de drogas ilícitas entre Bandas Emergentes Criminales o Grupos Armados Ilegales como un fenómeno desligado del conflicto armado que fue superado o que nunca existió.

Para el caso de Barrancabermeja, el Observatorio de Paz Integral (2013) denuncia la presencia de dos grandes estructuras paramilitares: los Botalones y los Urabeños, quienes operan en las comunas del área urbana y corregimientos aledaños, bajo la modalidad de combos, conformados por jóvenes quienes por dadivas económicas pasan a constituir el brazo armado de la mafia en el municipio. Estos “combos" operan en la mayoría de las comunas de Barrancabermeja, en donde "vienen intimidando a la población civil, e involucrando a la población más joven en actividades ilícitas, principalmente aquellas ligadas al microtráfico de estupefacientes" (párr.6). En palabras de un líder juvenil de la Corporación Juventud Raíces:

La violencia ha cambiado o ha mutado en una manera distinta al conflicto, es que ahora el problema de las drogas ha incrementado el problema de lado y lado, antes éramos víctimas ahora somos víctimas y victimarios, y somos utilizados por estos organismos para que hagamos todo ese aparato delincuencial que ha perjudicado a la juventud y la tiene al borde del abismo. Tanto como ser drogadicto o ser vendedor, es una estrategia de esos grupos para evadir la justicia pero a la larga están matando la juventud, están acabando los sueños de una sociedad (entrevista 18, Octubre 2012). 
Al indagar acerca de las principales problemáticas de la juventud en el municipio de Barrancabermeja, las personas entrevistadas hacen referencia a la drogadicción. Esta problemática ha tomado una nueva dinámica con respecto a años previos; afirman los jóvenes que anteriormente el consumo de drogas se realizaba a escondidas o clandestinamente. Hoy se han constituido zonas de venta y consumo de droga, conocidas por la comunidad con el nombre de "Ollas".

La drogadicción se veía en unas partes, que digamos era como a escondidas, pero ya después pasa el tiempo y la población se asienta en un lugar que es conocido acá en Barrancabermeja como "la olla" y entonces todo el mundo lo sabe, que allá en la olla en la comuna 1, llegando al muelle, allá están los jóvenes consumiendo (entrevista 4, Septiembre 2012).

\section{Violencia intrafamiliar, salud sexual y reproductiva}

Conexa a las problemáticas descritas, la prostitución ha venido afectando a la población juvenil especialmente a las mujeres. Se asocia esta problemática no sólo al creciente interés de los adolescentes y jóvenes por ejercer la prostitución dentro de los círculos delincuenciales en lo que se mueve el dinero, sino también a la falta de oportunidades y la pobreza.

En este sentido, Vásquez (2009) identifica para el caso particular de Barrancabermeja como factores determinantes del comercio sexual a la pobreza, el desempleo y el desplazamiento forzado. Asimismo, el autor da claridad acerca de las circunstancias que llevan al ejercicio la prostitución, encontrando que existen personas que conscientemente ofrecen su cuerpo a cambio de una retribución monetaria, otras que se involucran de manera voluntaria y ocasional como alternativa económica, y por ultimo quienes entran al ejercicio de la prostitución de manera forzosa o víctimas de engaño.

Dentro de esta última tipificación se podría enmarcar lo que jóvenes y pobladores de Barrancabermeja denominan trata de personas o tráfico de mujeres, entendidas desde su óptica como la influencia que se ejerce sobre alguien para hacer parte del negocio de la prostitución. Tal como menciona un funcionario de la Oficina de Gestión Social de Merilectrica S.A:

Otro problema que tenemos son las chicas que se meten en el tráfico de mujeres, entonces las mal llamada "prepagos". Las chicas se están metiendo en ese asunto trayendo como consecuencia embarazos, hay un desorden en la comprensión de lo que es la vida sexual y reproductiva (entrevista 11, Octubre 2012).

Las personas entrevistadas consideran como alarmantes las cifras de embarazos en adolescentes y de incidencia de enfermedades de transmisión sexual. Al respecto, una ex- funcionaria de la Alcaldía Municipal (2004) menciona: 
No quiero dejar de lado el problema de la maternidad precoz en niñas y adolescentes, quienes engrosan luego los círculos de miseria, al no estar preparadas para asumir con responsabilidad su maternidad, sin apoyo del padre del bebé, que normalmente es otro menor de edad incapaz de asumir económicamente el sustento de un hijo, repiten la cadena de pobreza de la que provienen (entrevista 20, Mayo 2013).

El Centro de Estudios Regionales CER (2011) abordando esta problemática reporta que la participación de los nacimientos de mujeres entre los 15 y 19 años representa para el año 2009 un 23,69\% del total de nacimientos en Barrancabermeja. En el periodo 1998- 2009 hay una tendencia general que apunta al aumento de embarazos en jóvenes en el rango de edad entre los 15 y 19 años. De igual manera, el estudio precisa altas tasas de incidencia frente al VIH/ SIDA y enfermedades de trasmisión sexual en el municipio, preocupación compartida por Vásquez (2009) quien a partir de pruebas realizadas por la secretaria de salud local con respecto a la seroprevalencia, demuestra un crecimiento sostenido de la epidemia de VIH, así como una feminización y rejuvenecimiento (aumento de casos en jóvenes entre 15 a 25 años) de la enfermedad, razón por la cual plantea la necesidad de abordar esta problemática desde un enfoque de género.

Entre tanto, una de las causas encontradas por el autor precitado para explicar la feminización de la epidemia de VIH en Barrancabermeja, es la existencia de una cultura machista, "sustentada en relaciones de desigualdad de género hacia la mujer en la sociedad, y el control social que se ejerce en el manejo o papel negociador de la mujer frente a las relaciones sexuales y de su cuerpo" (Vásquez, 2009, p. 79).

Esta desigualdad en el poder de negociación de la mujer frente al hombre también se evidencia en las relaciones establecidas en el hogar. Según Aguilera (2011) en Barrancabermeja el mayor número de agresiones al interior de las familias están dirigidas contra niños y mujeres jóvenes, entre los 21 y 30 años. Entonces, a pesar que tan solo algunos de los entrevistados identifica la violencia intrafamiliar como una problemática juvenil, no se puede obviar que esta "prevalece en un 54\% de los hogares de Barrancabermeja, siendo la de mayor ocurrencia la violencia física, en un $45 \%$, seguida por la violencia psicológica, con $44 \%$, y finalmente la violencia sexual, en 11\%" (Aguilera, 2011, p.138).

\section{Educación, empleo y orientación de vida}

Las personas entrevistadas hacen referencia al desempleo y la educación como problemática actual de la juventud. La deserción escolar en el municipio de acuerdo con cifras de la Cámara de Comercio de Barrancabermeja en el año 2011 para los grados $6^{\circ}$ y $9^{\circ}$ de educación secundaria es de un $18 \%$, y un $31 \%$ para los grados $10^{\circ}$ y $11^{\circ}$, casos explicados en un $66 \%$ por la búsqueda de empleo, la falta de dinero y el alto costo de la educación. 
Por otro lado, el sector educación pese a que ha evolucionado favorablemente en cobertura, la situación no deja de ser compleja en términos de calidad. Hay una marcada diferencia en la calidad educativa entre instituciones públicas y privadas, puesto que los resultados en las pruebas de conocimientos generales aplicadas a estudiantes de último año de educación secundaria en instituciones públicas son considerablemente bajos, dificultando el acceso de los jóvenes a la educación superior.

Según el Centro de Estudios Regionales- CER para el año 2012 en Barrancabermeja la oferta en educación superior es significativa y alcanza una tasas de cobertura bruta aproximada de 56\%, comparada con la tasa nacional de 2011 de 40,3\%. Sin embargo, se constata que los jóvenes consideran que la oferta académica no es la que necesitan los jóvenes y la región.

Ahora bien, la población joven que logra ingresary terminar una carrera profesional no tiene facilidad de acceso al mundo laboral. De acuerdo a cifras suministradas por el CER, para el año 2011 un 29,37\% de los jóvenes en Barrancabermeja se encontraban en situación de desempleo, un $11,2 \%$ por encima del promedio municipal. Se enfrentan los jóvenes a la falta de oportunidades laborales con el agravante de su poca experiencia y el no poseer vínculos con ciertos círculos sociales que les permitan acceder a puestos de trabajo.

Un miembro de la pastoral social de la Diócesis de Barrancabermeja menciona que los jóvenes ven sesgados sus sueños por la dificultad de acceder a un empleo, lo cual se explica porque:

Como joven no tengo la posibilidad, porque no tengo la experiencia, porque para entrar al mundo de la refinería, yo debo tener una experiencia. Poca es mi oportunidad si yo no tuve un manejo social para que me permitiera entrar allí (entrevista 7, Septiembre 2012 ).

Mencionan los jóvenes que para acceder a puestos de trabajo profesional y de alta cualificación son contratadas personas de otras zonas del país. Existe, por ejemplo, una bolsa de empleo administrada por la Alcaldía Municipal (2004) en la que se ofertan puestos de trabajo calificados y no calificados. Sin embargo, esta bolsa de empleo está abierta a nivel nacional, lo que reduce las posibilidades de los profesionales locales. Por ende, las dificultades no están solo en el ingreso a la universidad sino también en la falta de oferta laboral profesional una vez terminado el nivel superior de educación.

En último lugar, los jóvenes no tienen una orientación vocacional y un proyecto de vida estructurado. Perciben los jóvenes que existe una desarticulación entre sus potencialidades o habilidades para el arte, la cultura y el deporte, y las oportunidades existentes para el aprovechamiento de las mismas, tanto en materia de disponibilidad de espacios físicos, como de incentivos para su fomento. Esto les impide poder vivir desde su vocación obligándolos a modificar parcialmente su plan o proyecto de vida, que estaría más sujeto a sus limitaciones económicas que a sus motivaciones personales. 


\section{Participación: las organizaciones juveniles y sus procesos de articulación}

El nuevo modelo de acumulación de riqueza en América Latina en detrimento del modelo de bienestar ha derivado en un aumento de la pobreza y la marginación en todas las esferas de la sociedad (Rivera, 2011). En este contexto se profundiza la problemática existente en los jóvenes quienes viven una etapa de construcción de su identidad laboral y personal a la vez que se enfrentan ante las aberrantes condiciones de exclusión y falta de oportunidades. En este sentido, la Comisión Económica para América Latina, (CEPAL, 2011) advierte de una constante formulación de demandas de los jóvenes con respecto a su participación en el proceso de desarrollo, a la vez que identifica la existencia de múltiples y simultáneas exclusiones que restringen su capacidad de acción y limitan la gestión de sus proyectos.

En efecto, los programas actuales suelen abordar a la juventud desde un enfoque tradicional que considera esta etapa como un paso a la adultez y preparación para el futuro, caso contrario, el trabajo desplegado en lo atinente a la formación ciudadana de los jóvenes y el fomento de su participación activa en el desarrollo es menor (Rodríguez, 2004). A pesar que un número significativo de países han puesto en marcha el diseño de políticas públicas de alcance nacional y estrategias centradas en la juventud, la gran mayoría no cuenta con las estructuras para brindar una efectiva participación de los y las jóvenes (Grupo de Trabajo Ad Hoc para la Juventud y los Objetivos del Milenio, 2005), es decir, propiciar un nivel de empoderamiento y autonomía: "los jóvenes desarrollan proyectos y propuestas propias, fijan objetivos, metodologías, códigos innovadores y buscan apoyos y asesorías cuando lo requieren" (Krauskopf, 2000, p.22 )

La participación juvenil debe ser observada y valorada no sólo por temáticas específicas, sino también por sus formas de expresión, bajo la comprensión de su heterogeneidad, la complejidad de su panorama actual y un mundo cambiante, en donde los jóvenes reciben constantemente estímulos que impactan y forjan su desarrollo. Por ello, se precisa abordar con especial detenimiento las nuevas formas de organización juvenil, acciones colectivas o "conjunción de individuos que se unen para actuar de manera colegiada por una motivación compartida o persiguiendo un fin" (Delgado, Ocampo \& Robledo, 2008, p. 203) que habitualmente responde a sentimientos de injusticia, pertenencia, la lealtad y búsqueda de reconocimiento.

\section{Equipo de Trabajo Juvenil de la Comuna Siete}

El Equipo de Trabajo Juvenil de la Comuna Siete- ETJ7 fue un colectivo juvenil informal constituido en el año 2004. Allí concurrían jóvenes apoyados por la empresa privada, la iglesia católica y miembros de la Organización Femenina Popular (OFP) quienes sintieron la necesidad de trabajar en un interés común de un colectivo juvenil que fuese capaz de generar acciones enfocadas a construir un plan de vida y arrebatarle jóvenes a la guerra. 
En el año 1996, la Oficina de gestión social de la empresa Merilectrica S.A inicia un diálogo directo con la comunidad, específicamente en diez (10) Barrios de la Comuna Siete: Villarelis I, II y III, el Barrio Pablo Acuña, 9 de abril, El Campin, Divino niño, María Eugenia, 16 de marzo y El Prado. En estos diálogos fue evidente que los jóvenes carecían de reconocimiento y aprobación por parte de los adultos. No eran considerados como participantes y aportantes en los procesos que existían en Barrancabermeja en medio del conflicto armado.

Como respuesta, la empresa implementa el programa de formación de niños y jóvenes logrando la conformación de Juventud Activa, un conjunto de diez grupos juveniles y diez grupos de niños, uno por cada barrio de su área de influencia. En las actividades desarrolladas con los grupos juveniles enfocadas a hablar acerca de su vida y la problemática del reclutamiento forzado nace la necesidad de incorporar talleres de formación integral para ampliar la mirada de los jóvenes sobre el mundo exterior, dejando atrás esa visión local que los limitaba.

Al principio no había una costumbre de unión y expectativas de los jóvenes en poder contar con espacios para expresarse y compartir con jóvenes de otros barrios. Curiosamente frente a tener problemáticas sociales similares los jóvenes se discriminaban unos a otros dependiendo del barrio de procedencia. La idea era que los jóvenes entendieran que poseían capacidades, aptitudes y actitudes para desempeñarse socialmente, que había caminos por emprender a pesar del conflicto armado y que debían existir oportunidades para ellos (entrevista 7, septiembre 2012)

La participación juvenil en la Comuna Siete se ve marcada por el deterioro del orden público a raíz de la masacre del 16 de mayo de 1998. La entrada del paramilitarismo a la zona oriental del municipio de Barrancabermeja ocasionó el arribo de organizaciones no gubernamentales en pro de la defensa de los derechos humanos a la vez que consolida la presencia en la zona del Programa de Desarrollo y Paz del Magdalena Medio y la empresa privada.

En la Comuna Siete sus pobladores vivieron un miedo generalizado y eran reacios a asistir a eventos al aire libre o alguna actividad que significara aglomeración. En efecto, cualquier actividad se tornaba en temor e incertidumbre. Esto llevó a los jóvenes a preguntarse, ¿cómo hacer para perder ese temor? Los jóvenes transformaron sus interrogantes en acciones desarrollando actividades culturales en la búsqueda de estimular el uso adecuado del tiempo libre y aprovechar aquellos lugares que eran estigmatizados a causa de la violencia.

Ahora bien, los jóvenes de la Comuna Siete encuentran finalmente una motivación para articularse en el interés de incidir en el proceso de la Ciudadela Educativa del Magdalena Medio, esta iniciativa surge a desde la comunidad frente a la necesidad de construir una institución educativa con énfasis agropecuario pensada como alternativa para los niños y jóvenes de la comuna, quienes en su mayoría pertenecían a familias campesinas desplazadas por la violencia. 
Si bien la Ciudadela Educativa era un proyecto liderado por los líderes de las juntas de acción comunal, los jóvenes se veían reflejados en este espacio. Esta propuesta emblemática que fue coordinada por un grupo gestor encabezado por los presidentes de las juntas de acciones comunales, docentes y madres de familia, brindó posteriormente a los jóvenes la oportunidad de participar en la planeación de la Comuna Siete, en el denominado Espacio de Planeación Global y contando con un espacio físico de trabajo en Paloka, sede del proceso social construida en el año 2000 con recursos provenientes de una donación de la embajada de Japón en Colombia.

Las acciones del ETJ7 se estructuraron alrededor de tres ejes: educativo, social y productivo. En el 2004 gracias a la gestión del Programa de Desarrollo y Paz del Magdalena Medio, la Unión Europea destina recursos para la construcción del Colegio Ciudadela Educativa, y de forma simultánea a la construcción de esta Ciudadela se hace una recuperación ambiental de aproximadamente 60 hectáreas que son asumidas como un pulmón verde; la recuperación de estos bosques con siembras masivas tenía la finalidad de impulsar proyectos productivos sostenibles para la comunidad.

El Equipo de Trabajo Juvenil de la Comuna Siete que se consolida en el año 2004 participa en este proceso logrando generar recursos para la sostenibilidad de las organizaciones juveniles a través de oportunidades laborales para los jóvenes, se destacan la constitución de una finca de ganadería semiestabulada con aportes de la empresa Merilectrica S.A, una planta procesadora de yuca y una planta de abono orgánico con apoyo de la Unión Europea.

Con respecto a los ejes educativo y social, para el año 2004, la agencia de cooperación Sueca CIVIS financia el proyecto Herramientas para la Paz que consiste en la formación de 30 jóvenes en el tema de resolución de conflictos y construcción de políticas públicas y sociales. Este proyecto permite ampliar la visión de las jóvenes acerca de la acciones a emprender en la comuna siete y construir políticas de participación; en este año, precisamente, el ETJ-7 se vincula formalmente a la Red de Jóvenes de Barrancabermeja, y en el marco de estas relaciones fue filmado un video titulado "Tranquilandia", una parodia en donde los jóvenes realizan una lectura crítica del ejercicio político en la ciudad; este video alcanzó una nominación al premio periodístico local Pluma de Oro, erigiéndose ganador en una de sus categorías.

El Equipo de Trabajo Juvenil de la Comuna Siete decae por un agotamiento del liderazgo que conllevó a la fragmentación del colectivo. Los jóvenes crecieron $\mathrm{y}$ no hubo quien pudiese tomar la experiencia y dar continuidad al proceso, no existió un relevo generacional. Sumado a esto, algunas organizaciones no se sentían reconocidas en el colectivo y otras al ver fraguar sus apuestas productivas simplemente desaparecen. La participación juvenil en la Comuna Siete continua, 
pero no desde un enfoque productivo y de incidencia en la agenda pública sino a través de organizaciones de carácter cultural y deportivo.

\section{Articulación Juvenil de Barrancabermeja}

La Articulación Juvenil de Barrancabermeja fue un colectivo juvenil informal constituido en el año 2008 y conformado en sus inicios por 12 organizaciones juveniles ${ }^{4}$ pertenecientes a las diferentes comunas del municipio de Barrancabermeja y sus corregimientos aledaños (zona rural). Sus objetivos eran el fortalecimiento interno de las organizaciones juveniles y el robustecimiento de la participación, la capacidad de gestión e incidencia de la juventud organizada en la agenda pública del municipio de Barrancabermeja. Este colectivo fue pensado como un espacio autónomo, con estructura e identidad propia en donde se articularán organizaciones, procesos y líderes juveniles alrededor del papel de los jóvenes como promotores de la no violencia, contando con el apoyo y acompañamiento del programa Comunas Territorio de No violencia, el movimiento ciudadano "Aquí estoy país" y la Pontificia Universidad Javeriana.

Los inicios de la Articulación Juvenil de Barrancabermeja se remontan a principios de la década pasada. En el año 2002, la Diócesis de Barrancabermeja creó la Comisión Cívica de Convivencia Ciudadana a solicitud de las organizaciones sociales quienes abogaban por la reconstrucción del tejido social. Esta comisión integrada por miembros de la sociedad civil se orientó a repensar la ciudad e impulsar la acción no violenta desde un trabajo directo con la comunidad. Señala A. P. Rodríguez, facilitadora del proceso de la Comisión Cívica Ciudadana:

La Diócesis como tal, genera [...] un proyecto que se llama la comisión cívica ciudadana. Esta Comisión Cívica Ciudadana parte de identificar que la sociedad civil de Barrancabermeja necesita un apoyo para que empiece nuevamente un proceso de ciudad. [...] es allí donde surgen dos proyecciones: una dirigida no solamente a esa sociedad civil organizada como gremios, como organizaciones sociales constituidas y reconocidas, si no también hacer un proceso directo en los barrios y en las comunas de Barrancabermeja (entrevista 7, septiembre 2012).

La Comisión Cívica de Convivencia Ciudadana desarrolló el programa Comunas Territorios de No violencia como una apuesta al empoderamiento de la comunidad. Para esta finalidad, adopta el concepto de no violencia entendido como un proceso de cambio de las personas en los diferentes ámbitos de la sociedad, quienes promueven la defensa de los derechos ciudadanos sin la necesidad de hacer uso de la violencia.

4 Escuela de Arte de Arte Vida Joven, Fundación Nuevo Amanecer, Cristo Salva, Luz y Vida, Actitud Juvenil, Dejando Huellas, Cofradía Juvenil, Corporación Juventud Sin Fronteras, Asociación Juvenil Némesis, Corporación Juventud Raizes, Corporación Taquichuyma y Asociación Juventud Rural 
El trabajo del programa Comunas Territorios de No Violencia inicia en un contexto caracterizado por "las muertes a antiguos militantes de las guerrillas, las limpiezas sociales y las normas de convivencia para controlar la población” (Comisión Cívica de Convivencia Ciudadana, 2009, p.6). En este ambiente, el programa se traslada a las comunas 4, 5 y 6 localizadas en el nororiente y suroriente de Barrancabermeja, en donde a través del uso de herramientas pedagógicas y acciones simbólicas busca eliminar del imaginario colectivo la existencia de dos Barrancabermeja: la del puente para allá y la del puente para acá.

En el transcurso de las actividades se destaca la presencia de los jóvenes, y es por esta razón que el programa decide vincular a los jóvenes entorno a la dinámica de la No Violencia y para ello, contando con el respaldo de la Pontifica Universidad Javeriana, capacitan a un grupo de jóvenes, en su mayoría miembros de organizaciones juveniles, como Promotores de la No Violencia. En la medida que las organizaciones juveniles lograron ser reconocidas por su papel en el Programa de Comunas Territorios de No Violencia se plantea la necesidad de crear "una estrategia que permita integrar a estas formas de organización juvenil por la no violencia un proceso donde se mantenga la autonomía de cada organización y donde se puedan llevar a cabo construcciones de imaginarios colectivos desde la perspectiva juvenil" (Comisión Cívica Ciudadana, p.115).

Así, para el año 2008, en el marco del VI Encuentro de la No violencia desde la perspectiva Juvenil nace la Articulación Juvenil de Barrancabermeja (AJB) definida como:

Un espacio de análisis, discusión, construcción y desarrollo de la dinámica juvenil del municipio, donde se encuentran diferentes organizaciones, procesos y líderes juveniles, promoviendo la participación, empoderamiento e incidencia del joven, y la suma de esfuerzos y recursos del orden gubernamental y no gubernamental, en torno al desarrollo de la juventud y la ciudadanía en general (AJB, 2009, p.2).

La Articulación Juvenil de Barrancabermeja adopta un modelo circular y transversal que buscaba garantizar su operatividad y funcionamiento. En esta estructura organizacional un coordinador era responsable por las acciones desarrolladas en cada una de las cuatro líneas de trabajo: 1. Propuestas y proyectos; 2. Comunicaciones; 3. Investigaciones; 4. Fortalecimiento organizacional y de liderazgos.

Las líneas de trabajo de la organización respondían a unos objetivos claros y previamente definidos. En ese sentido, en la línea de trabajo propuestas y proyectos eran formulados proyectos que correspondían a las apuestas comunes entre las diferentes organizaciones que conformaban el colectivo juvenil. Estos proyectos y acciones eran visibilizados por la línea de comunicaciones, encargada de la coordinación de los procesos de comunicación e información institucional (interna y externa) para la consolidación de la imagen y las relaciones públicas del colectivo. 
La línea de fortalecimiento organizacional y liderazgos fue dispuesta para la promoción y acompañamiento de las acciones puntuales de las organizaciones y el desarrollo personal, social e intelectual de los líderes juveniles. En último lugar se encontraba la línea de investigaciones, planteada con la finalidad de realizar estudios e investigaciones que contribuyeran al fortalecimiento del colectivo juvenil y el desarrollo local y regional en temas relacionados a la juventud.

Figura 1. Estructura organizacional de la Articulación Juvenil de Barrancabermeja

En la estructura organizacional existía un equipo dinamizador encargado de coordinar y acompañar el funcionamiento de las líneas de trabajo asumiendo el papel de facilitadores en la Articulación Juvenil de Barrancabermeja. Los coordinadores de las líneas de trabajo y los miembros del equipo dinamizador conformaban el comité operativo, organismo encargado de abrir la discusión de los temas que afectaban directamente el colectivo. Allí se socializaban las acciones y estrategias de cada una de las líneas de acción de acuerdo a las directrices y políticas definidas por la mesa de articulación central y la asamblea general. 
Estas dos últimas instancias mencionadas brindaban una mayor representatividad a las organizaciones y líderes juveniles participantes en el colectivo juvenil. La Mesa de Articulación Central tomaba un papel de relevancia al ser la encargada de elegir el comité operativo y hacer un seguimiento periódico de las acciones planteadas mientras que la Asamblea General era un espacio de análisis, planeación y evaluación del proceso en general.

En último lugar, tal como ilustra la Figura 1, en la parte externa del modelo circular existían cuatro (4) elementos: entes gubernamentales, entes no gubernamentales, club de amigos y el Consejo Municipal de Juventud. Estos elementos correspondían a aquellas entidades y/o personas que trabajaban de la mano o brindaban apoyo a la Articulación Juvenil de Barrancabermeja con el fin de aportar al desarrollo de sus objetivos. Un joven de la Corporación Juventud Raizes comenta al respecto que:

También, por fuera de ese círculo hay como cuatro elementos puntuales que teníamos nosotros como apoyo. Uno eran los entes gubernamentales, que eran nuestro foco, primero de sostenibilidad y de mirar su oferta institucional hacia nosotros y como era recíproca. Los entes no gubernamentales, que son las ONGs (...); el Consejo Municipal de Juventud y hay un elemento que nosotros pusimos que es el club de amigos, ese club eran personas que podían ser de alguna organización o alguna $\mathrm{ONG}$, o pertenecer a las instituciones públicas pero que de manera individual como personas se sentían identificadas con el trabajo de nosotros; se vinculaban y eran parte de nosotros como club de amigos, es decir, esas personas que nosotros necesitábamos para una asesoría técnica en un tema puntual (entrevista 18, Octubre 2012).

Los jóvenes pertenecientes a las organizaciones juveniles que convergían en la Articulación de Barrancabermeja desarrollaban proyectos sociales y comunitarios de carácter local cofinanciados con recursos de entidades gubernamentales y organismos de cooperación internacional. Se destaca la participación de los jóvenes en el programa Comunas Territorio de No violencia, articulador de la Articulación Juvenil de Barrancabermeja, y el programa Viaje a pie, legión del afecto de la Oficina de Acción Social de la Presidencia de la República que dinamizaba las acciones juveniles en la medida que proveía a los jóvenes una pequeña remuneración que destinaban voluntariamente para la ejecución de sus actividades.

Las jóvenes miembros de la AJB participaron en dos importantes programas cofinanciados por la Alcaldía Municipal (2004): Acciones Alternativas para la Paz y Golombiao. Acciones Alternativas para la Paz brindaba acompañamiento, y en algunos casos apoyo a la conformación de grupos artísticos y culturales en los barrios y comunas del municipio de Barrancabermeja. Este programa buscaba generar alternativas para el buen uso del tiempo libre de los jóvenes y difundir un mensaje de paz a la sociedad a través de acciones culturales. En esencia para los jóvenes, era un programa en donde se intentaba "motivar a los jóvenes a pensar en la cultura como una opción de vida" (Entrevista) 
Por otro lado, Golombiao fue un programa de Colombia Joven implementado en Barrancabermeja para fortalecer los principios de la convivencia ciudadana, enfatizando en la participación de la juventud y la equidad de género. Los jóvenes no solo describen la interesante dinámica del programa sino que a la vez que identifican sus aportes:

[...] movilizar a los jóvenes en torno al tema del microfútbol y hacerlos reflexionar frente al tema de manejo de conflictos poniéndolos en una situación puntual que se presenta sin necesidad de generarla en el campo de juego, allí, ellos reflexionaban entorno a lo que sucedía. Entonces, al inicio se generaban acuerdos de cuáles eran las reglas del juego y cuáles eran las tradicionales; se manejaba el tema de género, por ejemplo, el primer gol lo tenía que meter una mujer, sino no era válido. Al final los equipos reflexionaban y entre ellos se asignaban una puntuación entorno a lo que había pasado frente al tema de convivencia más que en el juego..." (Entrevista 3, Septiembre 2012)

Un líder juvenil que se desempeñó como coordinador del programa en Barrancabermeja, destaca que Golombiao era:

[...] un proyecto que se enfocaba era a buscar las herramientas de cómo resolver los conflictos internos de los barrios y lograra acercar a la gente y que se conocieran. Cosas extraordinarias de equipos que nunca habían ido al llanito y que era un corregimiento, era un elemento que descubrimos, (...) logro pegar mucho fue el conocimiento del territorio, muchas veces vivimos en la ciudad y no conocemos un sector. Los muchachos se tenían que mover para los barrios y las comunas a ir a jugar los partidos, ir al llanito, ir al centro, y ellos empezaron a descubrir otro mundo distinto a la dinámica y que no era un proyecto competitivo sino que era pedagógico ( Entrevista 18, Octubre 2012 ).

En el año 2008, la juventud organizada propone a la administración municipal la realización del II Congreso del 4 de julio con motivo de la conmemoración del Día Internacional de la Juventud. La gestión realizada por los jóvenes es infructuosa, la administración municipal que en un primer momento se interés en la actividad incumple los compromisos acordados y lleva a cabo un evento conmemorativo sin el apoyo de las organizaciones juveniles. Ante esta situación, los jóvenes sientan su posición y con el apoyo de la universidad EAFIT, el Consejo Territorial de Planeación, el Consejo Municipal de Juventud y la empresa privada organizan el panel de discusión "Hablemos de ciudad".

El panel "Hablemos de Ciudad" a pesar de no contar con el apoyo económico de la Alcaldía Municipal logró la participación de aproximadamente 300 jóvenes. Se hizo evidente la capacidad de gestión y mayor poder de convocatoria del colectivo y sus organizaciones juveniles frente a la administración municipal. En vista de lo ocurrido, en el año 2009 la Corporación Juventud Raizes en representación de la Articulación Juvenil de Barrancabermeja firma un convenio de cooperación con la Alcaldía Municipal para la realización del II Congreso 4 de Julio "Jóvenes 
Construyendo ciudadanía”, convirtiéndose así en la primera organización juvenil del municipio de Barrancabermeja en operar recursos públicos.

La Articulación Juvenil de Barrancabermeja ve mermado el apoyo brindado por la Diócesis de Barrancabermeja promotora del programa Comunas Territorios de No violencia a raíz de la partida de organismos de cooperación internacional de la región del Magdalena Medio, especialmente del municipio de Barrancabermeja. Esta situación conllevó a que la administración municipal se convirtiera gradualmente en la fuente de recursos para el desarrollo de actividades relacionadas con la participación juvenil.

La culminación del convenio entre la Diócesis de Barrancabermeja y la Alcaldía Municipal para el desarrollo del programa Acciones Alternativas para la Paz imposibilito a la Diócesis seguir brindando un fuerte apoyo logístico al desarrollo de las actividades de las organizaciones juveniles. Adicionalmente, fue evidente para los jóvenes el desinterés de la administración municipal en promover el fortalecimiento de las organizaciones juveniles. Ante la escasez de recursos para llevar a cabo acciones puntuales, las organizaciones fueron debilitándose progresivamente al mismo tiempo que sus miembros asumieron nuevos roles y responsabilidades relacionadas a su desarrollo personal y profesional. Fue imposible sostener la dinámica del colectivo juvenil, sin embargo, se determinó para un futuro cercano la posibilidad de aunar esfuerzos entre las organizaciones en situaciones puntales que así lo requirieran.

\section{Situación actual de la participación juvenil en el municipio de Barrancabermeja: a modo de conclusión}

Las particularidades económicas, políticas y sociales del municipio de Barrancabermeja han conllevado a que los jóvenes de manera reiterada encuentren motivaciones para el desarrollo de procesos de participación. A finales de los años noventa, la juventud del municipio de Barrancabermeja enfoca sus acciones a la generación de espacios culturales como alternativa de solución a problemáticas asociadas al conflicto armado; y en años posteriores, con la aparición de experiencias de articulación que dieron lugar a la conformación de colectivos juveniles, los jóvenes emprenden la búsqueda de reconocimiento como actores importantes para el desarrollo local y comunitario, con el interés particular de incidir en la agenda pública.

Ahora bien, la participación juvenil en Barrancabermeja se ha reducido de manera considerable; se percibe una disminución del impacto de las organizaciones juveniles en cuanto a sus acciones e incidencia, situación atribuida por algunos líderes juveniles a un creciente desinterés y apatía de los jóvenes en aprovechar los mecanismos y espacios democráticas e institucionales de dispuestos por la ley. De ahí que se advierta de un desconocimiento de los jóvenes acerca de las implicaciones 
y repercusiones de las decisiones políticas en su bienestar y la importancia de promover una política pública en donde los jóvenes no sean solamente receptores de asistencia social sino actores en su propio desarrollo.

De otra parte, no existe articulación y continuidad de los procesos. Las instituciones que tienen el poder sobre las decisiones y los recursos para invertir en procesos que generen cambios sociales, se interesan más por proyectos puntuales que les signifiquen beneficios, por ejemplo, visibilidad. En el caso de la administración municipal sus programas y prioridades son cambiantes demostrando una falta de voluntad política dando lugar a periodos de transición que debilitan la participación juvenil en Barrancabermeja.

En este sentido, una queja muy persistente de los jóvenes en su discurso es la falta de apoyo a las iniciativas y propuestas de las organizaciones juveniles por parte de los estamentos públicos y privados. Señalan los jóvenes que en el municipio las dos grandes fuerzas que mueven el poder económico y de decisión son Ecopetrol y la Alcaldía Municipal, de ellas mencionan que se mueven de acuerdo a los intereses económicos que representan, olvidando de esa manera otras voces que propongan otro tipo de proyectos que no estén en el marco de la productividad económica. De esta manera, la dinámica es descrita como peleada, inestable y fraccionada. Cada nuevo gobernante, invierte los recursos en lo que considera es la prioridad, olvidando, en muchas ocasiones, procesos sociales que se han iniciado desde la administración anterior. Aun así, cuando existe de parte de las administraciones una inversión social que dinamiza algunos procesos, estos no cuentan siempre con la misma participación social en su planeación y ejecución. Debido a esto, hay una ruptura en la comunicación entre los entes políticos y las organizaciones juveniles que detectan y trabajan por la visibilización de las problemáticas sociales. Esta ruptura hace que no se perciba un verdadero trabajo mancomunado y eficiente en pro de la solución o manejo de las mismas, incluso se habla de un desconocimiento del trabajo social de base por parte de los actores políticos.

Si bien en los últimos años las organizaciones juveniles han logrado cierta injerencia a través de acciones puntuales hace falta la generación de verdaderos procesos sostenibles que sobrepasen los mandatos administrativos de los alcaldes. Las acciones de las organizaciones juveniles no han abarcado la problemática en su complejidad. La falta de visión holística de los jóvenes tanto de sus procesos organizativos como su rol de actores sociales en busca de una injerencia política, ha impedido incluso en algunos casos que sus propuestas y organizaciones sean sostenibles económicamente de tal manera que tengan un accionar continuado y con resultados a largo plazo.

Es también preocupante que algunas de las personas que iniciaron el trabajo en la década pasada siguen siendo hoy en día las mismas que lideran las organizaciones. Por ende, no se percibe una renovación generacional que permita oxigenar 
las organizaciones y que posibilite que nuevas personas, con otras visiones y percepciones, asuman nuevos roles de liderazgo.

En relación directa con la problemática de relevo generacional, es notorio en los jóvenes un discurso repetitivo y poco adaptado frente al abordaje de las problemáticas sociales. Al no existir oxigenación es perceptible un encallamiento de los ideales y las formas de actuar frente a la gestión de propuestas y proyectos, requiriéndose una referencia autocrítica.

\section{Referencias}

Aguilera, A. (2011). Prevalencia de la violencia intrafamiliar en el municipio de Barrancabermeja. Criminalidad, 53(2), 123-143.

Alcaldía Municipal de Barrancabermeja. (2004). Plan de Desarrollo Económico - Social 2004 - 2007 Con honestidad haremos más por Barrancabermeja. Barrancabermeja: Documento Interno.

Articulación Juvenil de Barrancabermeja. (2009). Informe de presentación. Documento interno.

Bendit, R. (2004). La modernización de la juventud y modelos de políticas de juventud en Europa. Construcción de Políticas de Juventud: análisis y perspectivas, 15. Disponible en: http://http://207.58.191.15:8180/xmlui/bitstream/ handle $/ 123456789 / 88 / \mathrm{T} \%$ D0\%92cnico_6.pdf?sequence=1\#page $=15$

Cámara de Comercio de Barrancabermeja. (2011). Encuesta social de hogares de Barrancabermeja. Disponible en: http://www.ccbarranca.org.co/contenido/ images/stories/BOLETIN/encuestashogares.pdf

Camargo, C. (2011). Jóvenes populares, tras el hilo de Ariadna. En C. E. Angarita Sarmiento, C. E. Jiménez Camargo, \& R. Zamudio Rozo, Habitando el Territorio. Jóvenes de la Sabana de Bogotá: Entre la Pobreza, el Conflicto y la Esperanza (págs. 75-105). Bogotá, D. C. ARFO. Disponible en: http://http://www.cactus. org.co/archivos/documentos/Publicaciones/serie/Libro\%20HABITANDO $\% 20$ EL\%20TERRITORIO\%20FINAL\%2018\%20abril.pdf\#page=75

Caraballo, M. (2011). Experiencias políticas y órdenes locales. Transformaciones del control paramilitar de la vida cotidiana en Barrancabermeja (Tesis Doctoral, Universidad Nacional de Colombia).

Cardona, L., \& Ariza, A. (2005). De la 28 A Pozo 7. Aproximación al conflicto urbano de la comuna 7 en la ciudad de Barrancabermeja. Resumen de Investigación. En Jóvenes, Conflictos Urbanos y Alternativas de Inclusión (págs. 79 - 95). Bogotá: Plataforma Conflicto Urbano y Jóvenes (PCUJ) - Agencia de Cooperación Sueca - CIVIS. 
CEPAL. (2011). Informe regional de población en América Latina y el Caribe 2011. Invertir en Juventud. Disponible en: http:/www.cepal.org/cgi-bin/getProd. asp?xml=/publicaciones/xml/8/47318/P47318.xml\&xsl=/tpl/p9f.xsl\&base=/tpl/ top-bottom.xsl

Comisión cívica de convivencia ciudadana (2009). Sistematización del proyecto fortalecimiento de la sociedad civil de la ciudad de Barrancabermeja. Diócesis de Barrancabermeja.

Delgado, R., Ocampo, A., \& Robledo, Á. M. (2008). La acción colectiva juvenil. Un modelo de análisis para su abordaje. Revista Ponto-e-vírgula, (4), 196-216.

Grupo de Trabajo Ad Hoc para la Juventud y los ODMs. (2005). La juventud y los objetivos de desarrollo del milenio. Desafios y oportunidades para su implementación. Disponible en: http://www.unicef.org/lac/Youth_and_the MDG-FinalReport-Spanish-10oct(1).pdf.

Krauskopf, D. (2000). Participación social y desarrollo en la adolescencia. San José: FNUAP.

Molina, L. (2008). Barrancabermeja: Segregación socioespacial y de desequilibrios funcionales. Cuadernos de Vivienda y Urbanismo. 1(2), 332-347

Moreno, C. A. (2006). De las movilizaciones sociales a las acciones colectivas por la paz, caso Barrancabermeja 1970 - 2000 (Tesis de Pregrado). Universidad Industrial de Santander, Bucaramanga.

Muñoz, G. (2003). Temas y problemas de los jóvenes colombianos al comenzar el siglo XXI. Revista Latinoamericana de Ciencias Sociales, Niñez y Juventud, 1(1), 145-180. Recuperado de http://scielo.org.co/pdf/rlcs/vln1/vln1a06.pdf

Observatorio de Paz Integral. (2013). La violencia se ensaña con la población de Barrancabermeja. Disponible en: http://www.observapaz.org/indexphp ?option $=$ com_content $\&$ view $=$ article $\& i d=262 \% 3$ Ala-violencia-se-ensana-con-lapoblacion-de-barrancabermeja\&catid=14\%3Aarticulos-conflicto\&Itemid $=18$

Quijano, C., \& Díaz, L (2004). El ejercicio del castigo en la relación entre actores armados ilegales y población civil: caso Barrancabermeja 1998 - 2003 (Tesis de Pregrado). Universidad Industrial de Santander, Bucaramanga.

Rivera, J. G. (2011). Tres miradas a la experiencia de la exclusión en las juventudes en América Latina. Revista Latinoamericana de Ciencias Sociales, Niñez y Juventud, 1 (9), 331 - 346.

Rodríguez, E. (2004). Políticas públicas de juventud en América Latina: empoderamiento de los jóvenes, enfoques integrados, gestión moderna y perspectiva generacional. En Construcción de Políticas de Juventud (p. 75-114). Manizales: Gente Nueva. 
Juventud en el municipio de Barrancabermeja: problemáticas socioeconómicas...

Vargas, A. R. (2009). Guerra civil en Colombia: el caso de Barrancabermeja. Guerra $y$ violencias en Colombia: herramientas e interpretaciones Bogotá, Colombia: CERAC, Pontificia Universidad Javeriana, 423-466.

Vásquez, S. L. (2009). VIH/Sida: Compromiso social. Una experiencia de visibilización del problema en el municipio de Barrancabermeja (Tesis de Pregrado). Bucaramanga:Universidad Industrial de Santander. 